\title{
Atmospheric Pressure Plasma Coating of Wood and MDF with Polyester Powder
}

\author{
Robert Köhler ${ }^{1, *, \dagger}$ (i) , Philipp Sauerbier ${ }^{2, *, \dagger}$, Holger Militz ${ }^{2}$ and Wolfgang Viöl ${ }^{1,3}$ \\ 1 Laboratory of Laser and Plasma Technologies, University of Applied Sciences and Arts, \\ Von-Ossietzky-Str. 99, 37085 Göttingen, Germany; wolfgang.vioel@hawk-hhg.de \\ 2 Wood Biology and Wood Products, Faculty of Forest Sciences, University of Goettingen, \\ Büsgenweg 4, 37077 Göttingen, Germany; hmilitz@uni-goettingen.de \\ 3 Application Center for Plasma and Photonics, Fraunhofer Institute for Surface Engineering and Thin Films, \\ Von-Ossietzky-Str. 100, 37085 Göttingen, Germany \\ * Correspondence: robert.koehler@hawk-hhg.de (R.K.); psauerb@uni-goettingen.de (P.S.) \\ Tel.: +49-551-3705-212 (R.K.); +49-551-3912-299 (P.S.) \\ + These authors contributed equally to this work.
}

Academic Editor: Mojgan Nejad

Received: 21 August 2017; Accepted: 10 October 2017; Published: 17 October 2017

\begin{abstract}
In this study, polyester powder based on iso- and teraphthalic acid was deposited with an atmospheric plasma jet. The powder was fed into the effluent plasma zone and deposited on European beech wood (Fagus sylvatica L.), Grand fir (Abies grandis Lindl.) and medium density fiberboard (MDF). The substrates were annealed subsequent to the coating process. To exclude decomposition of the polyester layers by the plasma treatment, the surface chemistry of the layers has been examined by X-ray photoelectron spectroscopy (XPS) and Fourier-transform infrared spectroscopy (FTIR) and compared with the polyester powder reference. Furthermore, topographical investigations were carried out using laser scanning microscopy (LSM). Adhesive strength of the layers was evaluated by dolly test and gloss measurements with a goniophotometer. The deposited layers showed no chemical changes compared to the reference. The adhesive strength of the layer met practical requirements of $>1 \mathrm{MPa}$. It was demonstrated that the deposition of a macroscopic layer is possible without a pretreatment or the usage of additives. Therefore this coating process by atmospheric pressure plasma for wood and wood based materials could represent an environmental-friendly alternative to conventional coating methods.
\end{abstract}

Keywords: plasma; wood; MDF; powder; coating; spectroscopy; gloss; adhesion strength

\section{Introduction}

Powder coating processes represent an alternative to conventional coating methods e.g., liquid paints. One of the advantages is that this method is environment-friendly by completely omitting volatile organic compounds and organic solvents [1-3]. Commonly used coating processes like electrostatic spraying, using a corona discharge, require electrically conductive substrate materials [4-6]. Using this technique powder and substrate are brought to different electric potentials. The powder is charged by electric current through the corona discharge and is sprayed on the grounded substrate [7-9]. Subsequently, the layer material is annealed to melt the powder and obtain a covering layer $[10,11]$.

Nonetheless, powder coating processes of wood and wood composites by corona discharge were shown in [12-14]. Badila et al. [14] describe the limited electrical conductivity of the surface as the main difficulty for wood powder coatings. In order to allow a proper coating of such surfaces, the surface resistance must be in the range of $10^{10}-10^{11} \Omega \cdot \mathrm{m}^{2} \cdot \mathrm{m}^{-1}$ [15]. If the electrical conductivity 
is not sufficient, pre-heating or priming with an electrically conductive wet lacquer provide possible solutions [15].

In this study it is shown that wood and wood based products can be coated with polyester powder without the necessity of a pretreatment. The layers were deposited by an atmospheric pressure plasma jet system. Furthermore, the effect of single and double depositions prior to annealing on layer thickness was under investigation.

For the verification of the successful layer deposition, the layers were examined regarding the layer thickness with a laser scanning microscope (LSM), as well as X-ray photoelectron spectroscopy (XPS) and Fourier-transform infrared spectroscopy (FTIR), verifying possible chemical changes of the coating material. Finally the pull-off strength (dolly test) and gloss of the layer were measured.

\section{Materials and Methods}

A modified atmospheric pressure plasma jet system (Plasmadust, Reinhausen Plasma GmbH, Regensburg, Germany) was used for the coating application. The system consists of a high-voltage power supply, an electrode setup with a self-developed spray nozzle and a brush disperser (RBG 2000, Palas $\mathrm{GmbH}$, Karlsruhe, Germany). Figure 1 shows a schematic cross-section of the electrode setup.

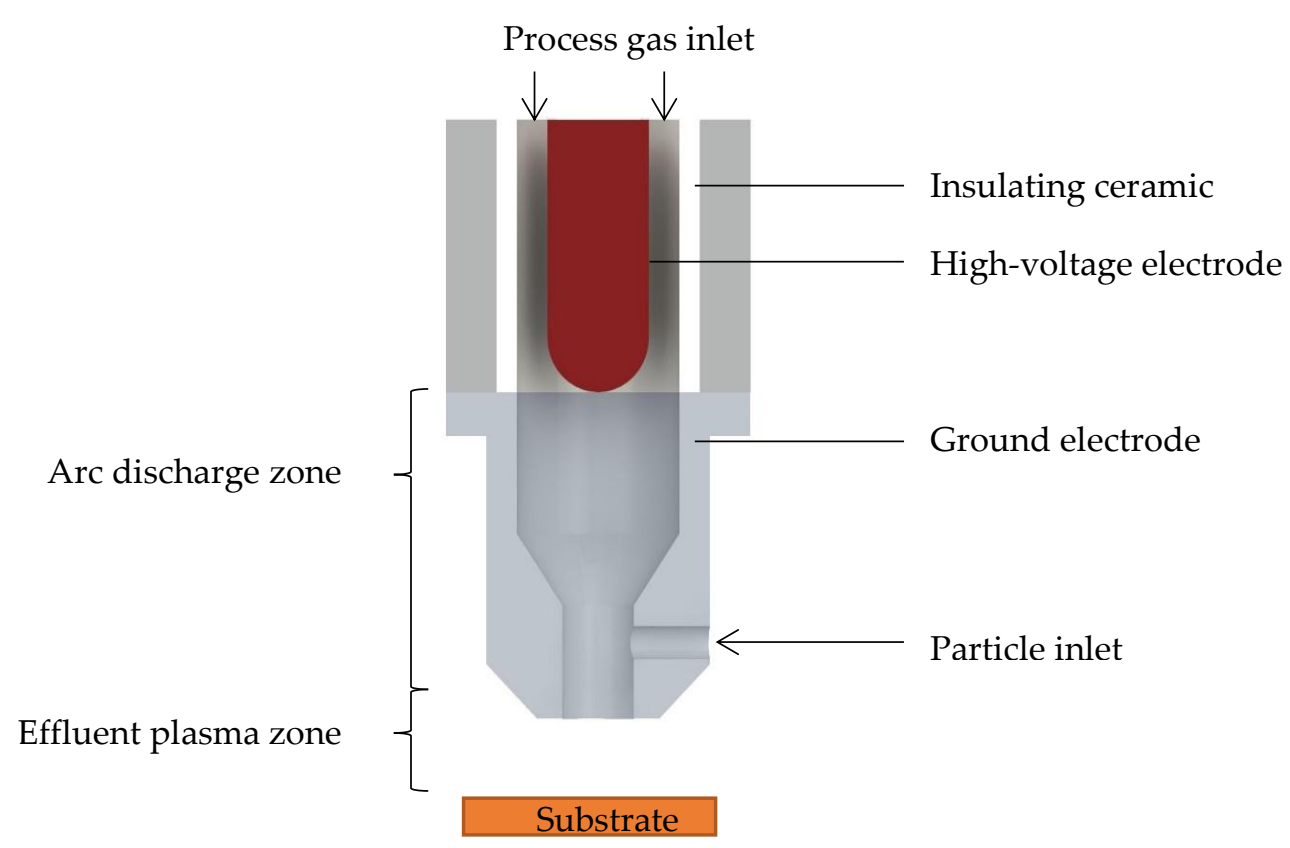

Figure 1. Cross-section of the electrode setup with particle inlet.

The plasma is formed as an arc between the high voltage electrode and the grounded spraying nozzle. The arc is ejected by the process gas, resulting in an afterglow effluent plasma, in which the particles are dispensed. Compressed air was used as process and powder carrying gas. To ignite the plasma, a pulsed voltage of approximately $15 \mathrm{kV}$ was applied, with the effective voltage being 2-3 kV. The pulse repetition frequency was $50 \mathrm{kHz}$ with a pulse duration of $5-10 \mu \mathrm{s}$ and a maximum input power of $2 \mathrm{~kW}$. Due to strong temperature gradients within the plasma effluent torch, the surface temperature of the substrates can be kept around $100{ }^{\circ} \mathrm{C}[16,17]$, hence temperature sensitive substrates, e.g., wood and wood based materials can be coated. The effluent plasma zone temperature was determined with a thermometer (Amprobe TMD-56, BEHA-AMPROBE GmbH, Glottertal, Germany) with a thermocouple type $\mathrm{K}$, working range from -50 to $1200{ }^{\circ} \mathrm{C}$ at a distance of $20 \mathrm{~mm}$ to the ground electrode. The introduced particles are a polyester powder (D50 $=45 \mu \mathrm{m}$ ), Interpon 610 MZ013GF (Akzo Nobel Powder Coatings GmbH, Arnsberg, Germany) based on isoand teraphthalic acid (TPA) polyester mix with a density of $120 \mathrm{~g} / \mathrm{m}^{3}$ [18]. For the coating process, 
the substrates were moved in meandering strips under the fixed spray nozzle. Table 1 shows the coating parameters.

Table 1. Coating parameters of the plasma application.

\begin{tabular}{cc}
\hline Parameter & Value \\
\hline Working distance & $20 \mathrm{~mm}$ \\
Process gas flow rate & $60 \mathrm{~L} / \mathrm{min}$ \\
Powder feed rate & $4.3 \mathrm{~m}^{3} / \mathrm{h}$ \\
Substrate scan speed & $40 \mathrm{~mm} / \mathrm{s}$ \\
Powder feed speed & $150 \mathrm{~mm} / \mathrm{h}$ \\
Process gas & Compressed air \\
\hline
\end{tabular}

European beech (Fagus sylvatica L.) and Grand fir (Abies grandis Lindl.) wood samples with dimensions of $26 \times 76 \times 4 \mathrm{~mm}^{3}$ (radial $\times$ longitudinal $\times$ tangential) as well as medium density fibreboard (MDF) with $26 \times 76 \times 12 \mathrm{~mm}^{3}$ were used as substrates. Prior to the experiments the specimens were conditioned in a $20{ }^{\circ} \mathrm{C} 65 \%$ relative humidity (RH) environment till a constant weight of the specimens on three following days was obtained. This lead to approximately $12 \%$ moisture content in European Beech, Grand fir and MDF specimens alike, as previous experiments showed. After the conditioning the following densities were measured: European beech $689 \mathrm{~kg} / \mathrm{m}^{3}$; Grand fir $366 \mathrm{~kg} / \mathrm{m}^{3}$; MDF $692 \mathrm{~kg} / \mathrm{m}^{3}$. European beech wood was chosen because of its good availability in German forests and the resulting necessity to develop new fields of use. Grand fir wood has a low resin content and therefore allows a good comparability between soft- and hard-wood for plasma treatments.

For the determination of the layer thickness, the samples were masked on one edge with tape prior to the coating process to obtain an uncoated area. Subsequently to the single or double coating process, the substrates were annealed for $10 \mathrm{~min}$ in the oven at $180^{\circ} \mathrm{C}$ based on the stoving schedule from AkzoNobel [18].

XPS measurements were performed on a PHI 5000 Versa Probe II (ULVAC-PHI, Chigasaki, Japan) using monochromatic Al-K $\alpha$ radiation with a photon energy of $1486.6 \mathrm{eV}$. The minimum detector resolution measured at the $\mathrm{Ag} 3 \mathrm{~d}_{5 / 2}$ peak is $0.45 \mathrm{eV}$. Detailed spectra of carbon $1 \mathrm{~s}(\mathrm{C} 1 \mathrm{~s})$, oxygen $1 \mathrm{~s}$ (O1s) and nitrogen 1s (N1s) with a pass energy of $46.95 \mathrm{eV}$, a step size of $0.1 \mathrm{eV}$ and a spot size of $200 \mu \mathrm{m}$ were recorded. In order to avoid charging effects, the measurements were carried out with neutralization of sample charging. The structures were fitted applying Voigt profiles after conducting a Shirley baseline subtraction.

The layer thickness was analyzed with a LSM (VK-X100, KEYENCE Deutschland GmbH, Neu-Isenburg, Germany) using a $20 \times$ objective. The prior to the coating process masked area as well as a coated area of $4000 \times 500 \mu^{2}$ were measured. The obtained data was processed in the form that image noise was removed and the tilt corrected. To gain the height information, the average height of coated to uncoated area $\left(1000 \times 400 \mu \mathrm{m}^{2}\right)$ was compared.

FTIR measurements of references as well as coated samples were performed on a PerkinElmer Frontier (PerkinElmer LAS (Deutschland) GmbH, Rodgau Jügesheim, Germany). The measurement was performed with diamond ATR (Specac Golden Gate GS 10515, Specac Ltd., Orpington, UK) in a range of $400-4000 \mathrm{~cm}^{-1}$, averaged over 64 scans with a resolution of $4 \mathrm{~cm}^{-1}$.

The pull-off strength was tested using the dolly test based on ASTM D 4541-02 [19] and DIN EN ISO 4624:2016-08 [20] with $20 \mathrm{~mm}$ dollies glued on with Araldite 2011 (Huntsman Advanced Materials LLC, Salt Lake City, UT, USA). The extraction was carried out using a hydraulic hand-held measuring device PosiTest AT-P (DeFelsko Corporation, Ogdensburg, NY, USA).

Differential scanning calorimetry (DSC) was used to determine the melting point of the used polyester powder. The measurement was performed with a Netszsch DSC 200 F3 (Erich NETZSCH $\mathrm{GmbH} \& \mathrm{Co}$. Holding KG, Selb, Germany). The sample were heated from 20 to $280^{\circ} \mathrm{C}$ in a nitrogen atmosphere with a step size of $10 \mathrm{~K} / \mathrm{min}$. 
A gloss measurement of the deposited coatings was carried out using a Rhopoint IQ goniophotometer (Rhopoint Instruments Ltd., Hastings, UK). The gloss measurements at $20^{\circ}, 60^{\circ}$ and $85^{\circ}$ were performed according to DIN EN ISO 2813:2015-02 [21].

\section{Results}

XPS measurements were performed for the chemical surface analysis and are presented in the following as atomic percent. The results of the quantitative analysis of C1s, N1s and O1s are shown in Table 2. The single-coated substrates are labelled with I, double-coated with II. In the cases of European beech and Grand fir the coating process resulted in an increase in carbon of 5\%-9\% and a decrease of oxygen of $5 \%-9 \%$ compared to the untreated wood references. The nitrogen content can be considered as constant. In case of MDF, the carbon content was reduced by $10 \%$ while the oxygen content was increased by $12 \%$. Nitrogen was reduced by approximately $2 \%$. The chemical composition of the coated wood and wood materials is comparable to the composition of the polyester reference.

Table 2. Chemical composition of coated wood and wood based materials compared to the reference material (XPS data).

\begin{tabular}{cccc}
\hline Substrate & C1s (at. \%) & N1s (at. \%) & O1s (at. \%) \\
\hline Beech I & 77.57 & 0.36 & 22.07 \\
Beech II & 76.11 & 0.75 & 23.15 \\
Beech reference & 71.29 & 0.46 & 28.25 \\
Grand fir I & 78.07 & 0.32 & 21.61 \\
Grand fir II & 77.52 & 0.54 & 21.94 \\
Grand fir reference & 68.74 & 0.46 & 30.8 \\
MDF I & 76.87 & 0.48 & 22.66 \\
MDF II & 76.10 & 0.92 & 22.98 \\
MDF reference & 86.85 & 2.65 & 10.49 \\
Powder reference & 78.52 & 0.42 & 21.06 \\
\hline
\end{tabular}

Figure 2 shows an example of the $\mathrm{C} 1 s$ and $\mathrm{O} 1 s$ peaks for the polyester reference. The $\mathrm{C} 1 s$ peak is comparable to TPA, from which polyesters are synthesised. The sample had 3 significant structures in the $\mathrm{C} 1 \mathrm{~s}$ peak. The spectrum was shifted to the main peak of $\mathrm{C} 1 \mathrm{~s}$ at $284.8 \mathrm{eV}$ [22]. The main peak can be assigned to the phenylic carbon $(\mathrm{C}=\mathrm{C} ; \mathrm{C}-\mathrm{C})$ [23], with an FWHM of $1.41 \mathrm{eV}$. The bonding energy of $286.19 \mathrm{eV}$ was not found in the $\mathrm{C} 1 \mathrm{~s}$ core level spectrum of TPA [24]. Possible explanations might be final state effects or a partial decomposition of the TPA molecules on the substrate's surfaces [25].
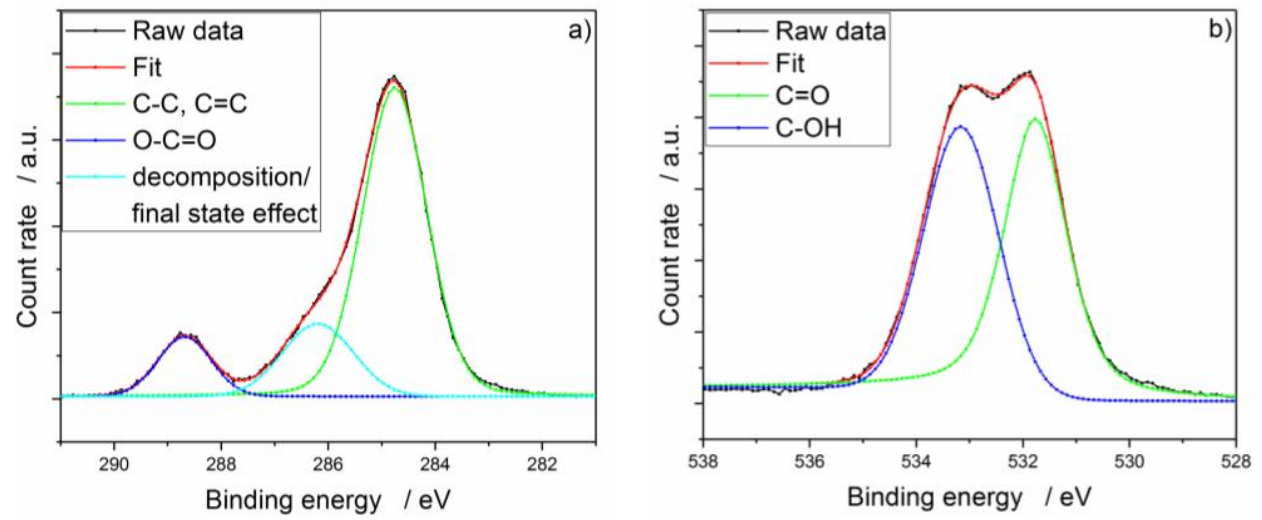

Figure 2. XPS detail spectra of polyester reference: (a) C1s peak and (b) O1s peak.

The third structure found around $288.68 \mathrm{eV}$ with FWHM $1.17 \mathrm{eV}$ can be identified as carboxyl group $(\mathrm{O}-\mathrm{C}=\mathrm{O})[24,26]$. In the $\mathrm{O} 1 \mathrm{~s}$ peak, the two structures were seen at 531.76 and $533.16 \mathrm{eV}$ with 
an FWHM of 1.40 and $1.64 \mathrm{eV}$. These structures correspond to carbonyl $(\mathrm{C}=\mathrm{O})$ and hydroxyl groups $(\mathrm{C}-\mathrm{OH})[23,24]$.

Figure 3 displays all $\mathrm{C} 1 \mathrm{~s}$ and O1s spectra of the tested samples. The coated samples showed an increase of the carboxyl group in the $\mathrm{C} 1 \mathrm{~s}$ peak compared to the respective references. In the $\mathrm{O} 1 \mathrm{~s}$ peak the species $\mathrm{C}=\mathrm{O}$ and $\mathrm{C}-\mathrm{OH}$ indicate a polyester layer.
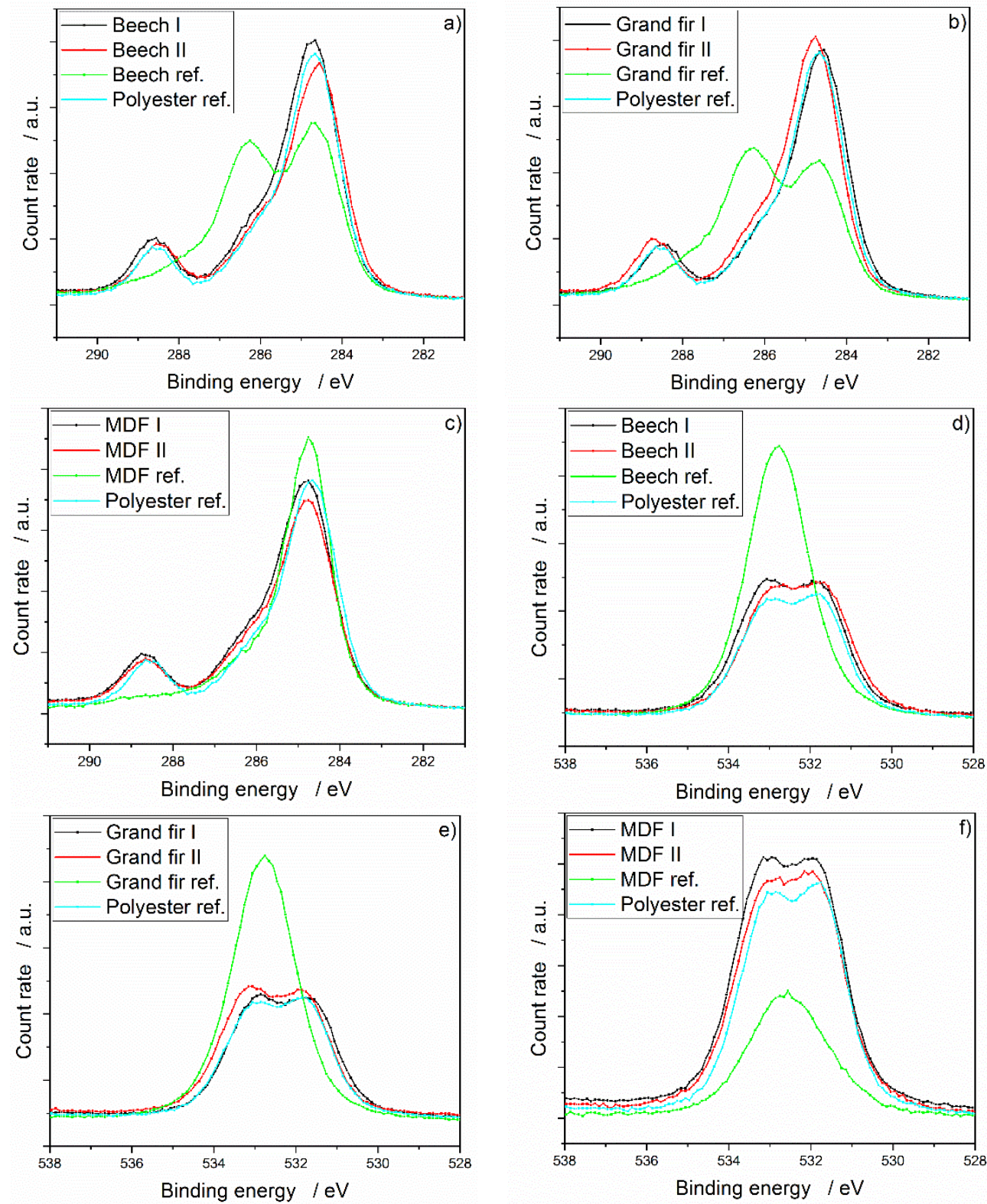

Figure 3. Comparison of XPS measurements of untreated reference, single-, double-coated and polyester reference: (a) C1s European beech; (b) C1s Grand fir; (c) C1s MDF; (d) O1s Beech; (e) O1s Grand fir; (f) O1s MDF.

The recorded FTIR spectra $(N=3)$ show clearly that there are no significant differences in the chemical structure between powder reference and coated samples. This applies to European beech, Grand fir and MDF alike. The spectra for European beech are shown in Figure 4 as an example. 


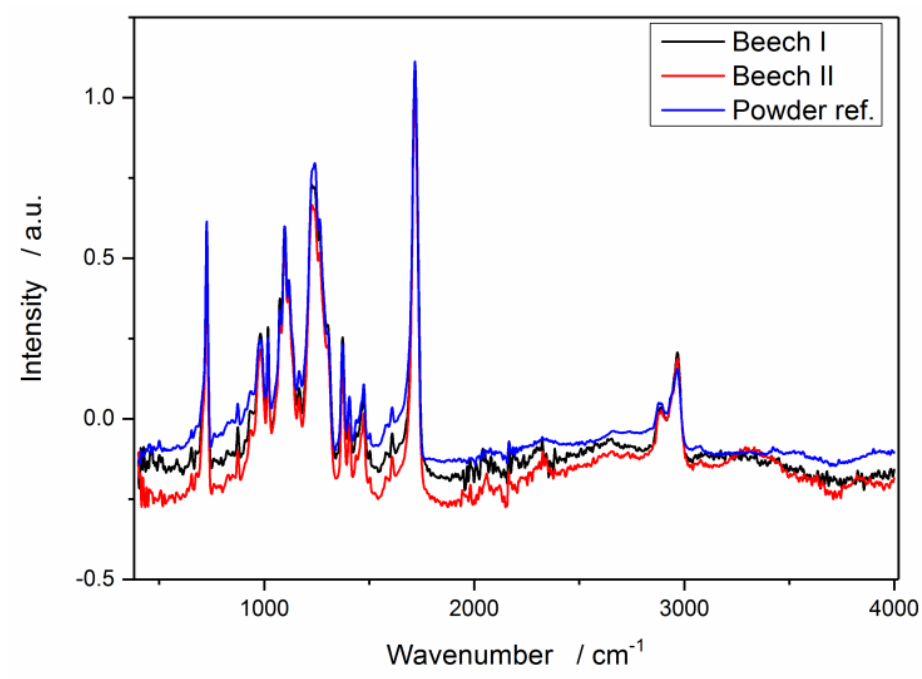

Figure 4. Comparison of FTIR spectra of single- and double-coated beech and the powder reference. All spectra are corrected by moving average baseline subtraction.

However, spectra of the untreated substrate surfaces and the powder reference show two completely different spectra. By way of example, the broad $\mathrm{OH}$ stretching peak in the region of $3300 \mathrm{~cm}^{-1}$, which is present in the substrate but does not occur in the polyester, should be mentioned here Figure 5.

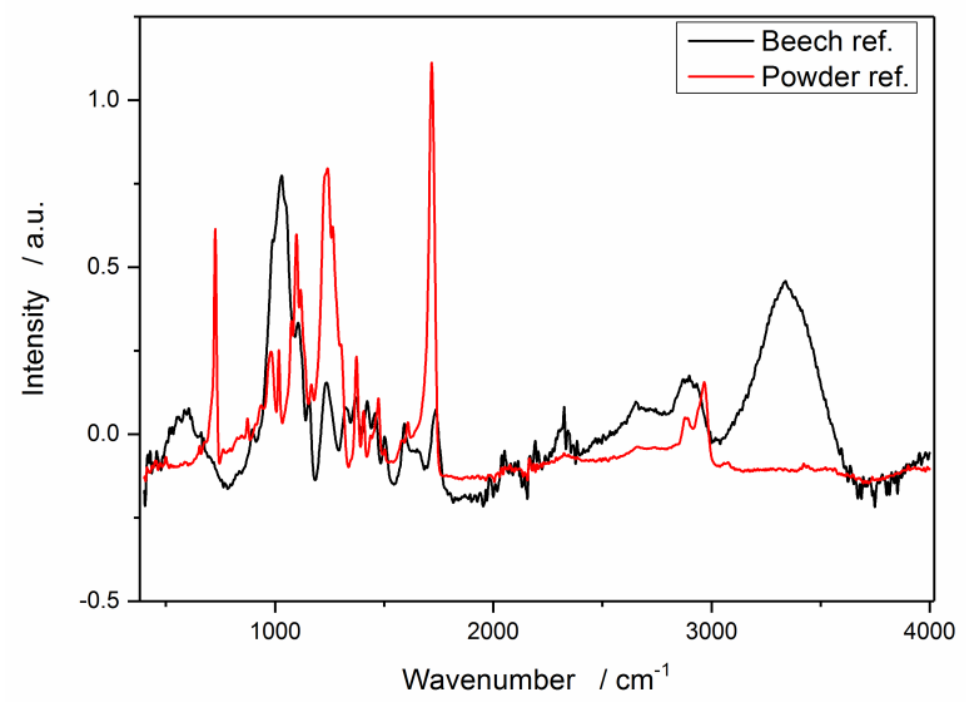

Figure 5. FTIR spectra of uncoated European beech and the powder reference.

Figure 6 shows the average layer thickness of the coated samples. The single-coated substrates exhibited a layer thickness of approximately $14 \mu \mathrm{m}$, whereas the double-coated substrates show approximately $22 \mu \mathrm{m}$. This corresponds to a layer growth of about $37 \%$ after a second treatment. 


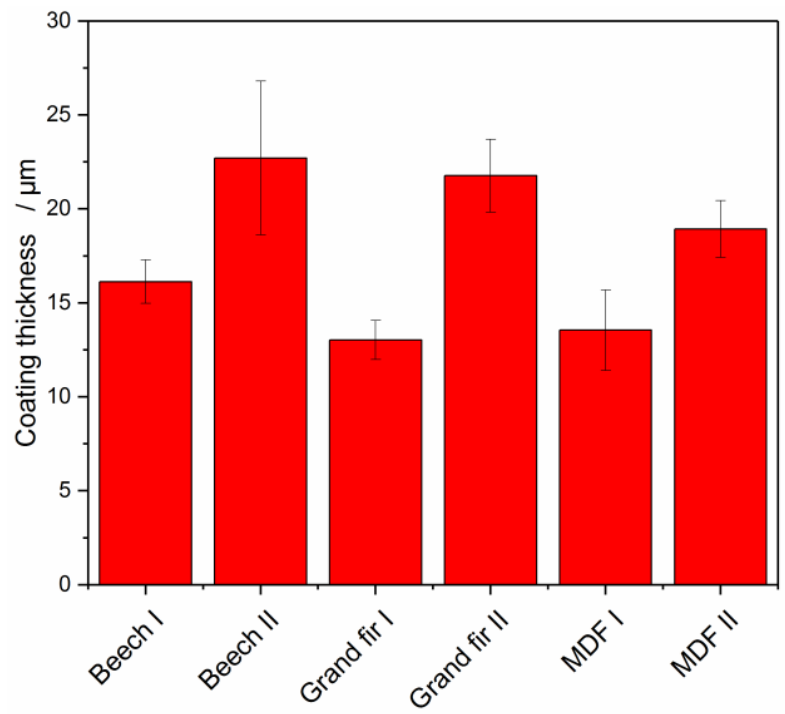

Figure 6. LSM data showing the coating thickness of single- and double-coated European beech, Grand fir and $\operatorname{MDF}(N=10)$.

The dolly test showed that, apart from a statistical outlier, the required practical minimum pull-off strength of $1 \mathrm{MPa}$ could be achieved. Figure 7 displays the distribution of the dolly test measurement as a box plot. The pull-off tests on most of the coated Grand fir samples did already show a cohesion failure. For MDF samples only cohesion failures occurred. Therefore, the lift-off strength might be partially above the values shown in Figure 7.

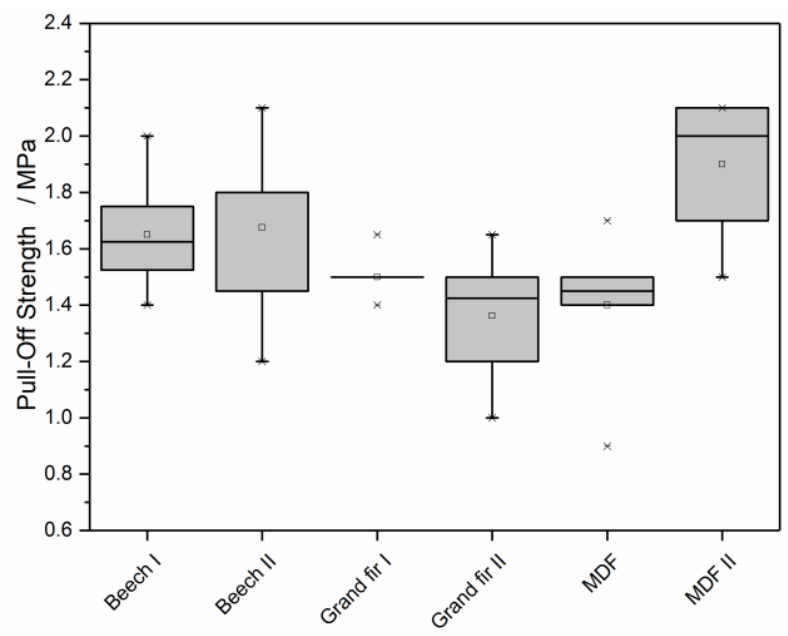

Figure 7. Pull-off strength of single and double-coated European beech, Grand fir and MDF $(N=10)$.

Table 3 illustrates the gloss measurements. The gloss values at the $60^{\circ}$ angle were all below 30 gloss units (GU), suggesting that the test pieces are predominantly matte. The degree of glossiness at $85^{\circ}$ is considered for a comparison of the test specimens. In case of Grand fir and MDF, an increase in the gloss was noticed. Comparing single to double-coated substrates, a doubling of the gloss value was ascertained. In case of European beech the degree of glossiness decreases with a second coating while the degree of glossiness increased from 9.2 to $12.8 \mathrm{GU}$ with a single coating. 
Table 3. Gloss measurements of coated and uncoated substrates $(N=10)$.

\begin{tabular}{ccc}
\hline Substrate & $\mathbf{6 0}^{\circ} \mathbf{( G U )}$ & $\mathbf{8 5}^{\circ} \mathbf{( G U )}$ \\
\hline Beech I & $21.2 \pm 3.8$ & $12.8 \pm 2.5$ \\
Beech II & $10.3 \pm 2.0$ & $7.5 \pm 1.8$ \\
Beech reference & $4.8 \pm 0.6$ & $9.2 \pm 2.3$ \\
Grand fir I & $12.1 \pm 3.6$ & $3.5 \pm 1.7$ \\
Grand fir II & $18.5 \pm 5.2$ & $7.1 \pm 1.8$ \\
Grand fir reference & $5.4 \pm 0.9$ & $3.6 \pm 1.8$ \\
MDF I & $2.9 \pm 0.7$ & $0.7 \pm 0.3$ \\
MDF II & $3.81 \pm 1.0$ & $1.1 \pm 0.5$ \\
MDF reference & $1.9 \pm 0.1$ & $0.34 \pm 0.1$ \\
\hline
\end{tabular}

DSC measurements revealed a melting point of the polyester powder of $59.2^{\circ} \mathrm{C}$. The temperature of the effluent plasma discharge at a $20 \mathrm{~mm}$ distance was $123.5^{\circ} \mathrm{C}$.

\section{Discussion}

The XPS and FTIR measurements indicate that the deposited layers are chemically identical compared to the powder reference. This is true for single and double treated substrates. Despite the high energy which is injected due to the plasma, destruction or decomposition of the powder can be ruled out. This is verified by the XPS data showing the chemical composition and the chemical structure data obtained with FTIR measurements. This is verified by the XPS as well as the FTIR data, showing clearly the similarities of the chemical composition or chemical structure of processed/unprocessed powders, respectively.

The results from LSM measurements show that macroscopic coating layers can be produced which are influenced in thickness by the repetition of the coating process. While a single deposition process exhibits a layer thickness of approximately $14 \mu \mathrm{m}$, a second deposition leads to an increase of about $8 \mu \mathrm{m}$. This effect is currently under investigation.

The obtained layers meet the practical requirements of a coating's pull-off strength of $1 \mathrm{MPa}$, according to dolly test. Especially for MDF the pull-off strength of the layer is above the required (>0.6 MPa) internal bond strength (DIN EN 319:1993-08 [27]). The bonding strength of the layer to the surface exceeds the internal bonding of the material. The increased temperature during the plasma treatment might be beneficial for adhesion: Measurements of the plasma temperature during the coating process and the melting point of the powder show that during the coating process higher temperatures are generated than are required for the melting of the powder. It can therefore be assumed that the particles have already been partially melted by the plasma coating process and thus adhere to the substrate surface even before the annealing process. This may result in a synergy effect which reduces the energy and time requirements of the annealing and thus minimizes the material stress.

\section{Conclusions}

The study revealed that the plasma jet process is an enabling technology for deposition of a macroscopic coating layer of polyester on various, non-conducting wood and wood materials. The deposition process is independent of the electrical conductivity and the thickness of the substrate and can take place without the application of additives or other pretreatments.

The resulting layers do not differ chemically from the unprocessed powder references. The adhesion of the layer is satisfying with an average pull-off strength of $>1 \mathrm{MPa}$.

The object of current research is, to investigate the positive synergy effect of the plasma treatment with the subsequent annealing process in regard of the annealing method and the treatment time.

Acknowledgments: This work was carried out within the framework of the research project "PlaNaWood2" (funding reference No. 03XP0015A/B) with financial support from the German Federal Ministry of Education and Research. The authors further thank Akzo Nobel Powder Coatings GmbH for providing the used powder material. 
Author Contributions: Robert Köhler and Philipp Sauerbier conceived, designed and preformed the experiments, and analyzed the data; Robert Köhler, Philipp Sauerbier, Holger Militz and Wolfgang Viöl discussed the results; Holger Militz and Wolfgang Viöl contributed reagents/materials/analysis tools; Robert Köhler and Philipp Sauerbier wrote the paper; Holger Militz and Wolfang Viöl ultimatively revised the paper.

Conflicts of Interest: The authors declare no conflict of interest.

\section{References}

1. Pearnchob, N.; Bodmeier, R. Dry polymer powder coating and comparison with conventional liquid-based coatings for Eudragit ${ }^{\circledR}$ RS, ethylcellulose and shellac. Eur. J. Pharm. Biopharm. 2003, 56, 363-369. [CrossRef]

2. Rossi, S.; Fedel, M.; Petrolli, S.; Deflorian, F. Accelerated weathering and chemical resistance of polyurethane powder coatings. J. Coat. Technol. Res. 2016, 13, 427-437. [CrossRef]

3. Belder, E.; Rutten, H.; Perera, D. Cure characterization of powder coatings. Prog. Org. Coat. 2001, 42, $142-149$. [CrossRef]

4. Misev, T.; van der Linde, R. Powder coatings technology: New developments at the turn of the century. Prog. Org. Coat. 1998, 34, 160-168. [CrossRef]

5. Barletta, M.; Vesco, S.; Trovalusci, F. Effect of the substrate and interface on micro-scratch deformation of epoxy-polyester powder coatings. Prog. Org. Coat. 2012, 74, 712-718. [CrossRef]

6. Piazza, D.; Silveira, D.S.; Lorandi, N.P.; Birriel, E.J.; Scienza, L.C.; Zattera, A.J. Polyester-based powder coatings with montmorillonite nanoparticles applied on carbon steel. Prog. Org. Coat. 2012, 73, 42-46. [CrossRef]

7. Radhakrishnan, S.; Sonawane, N.; Siju, C.R. Epoxy powder coatings containing polyaniline for enhanced corrosion protection. Prog. Org. Coat. 2009, 64, 383-386. [CrossRef]

8. Gavrilova, V.A.; Kashapov, N.F.; Kashapov, R.N. Plasma application of protective polymer-powder coatings to ultrasonic sensors. Biomed. Eng. 2011, 45, 198-200. [CrossRef]

9. Hedayati, M.; Salehi, M.; Bagheri, R.; Panjepour, M.; Naeimi, F. Tribological and mechanical properties of amorphous and semi-crystalline $\mathrm{PEEK} / \mathrm{SiO}_{2}$ nanocomposite coatings deposited on the plain carbon steel by electrostatic powder spray technique. Prog. Org. Coat. 2012, 74, 50-58. [CrossRef]

10. Kalaee, M.; Akhlaghi, S.; Nouri, A.; Mazinani, S.; Mortezaei, M.; Afshari, M.; Mostafanezhad, D.; Allahbakhsh, A.; Dehaghi, H.A.; Amirsadri, A.; et al. Effect of nano-sized calcium carbonate on cure kinetics and properties of polyester/epoxy blend powder coatings. Prog. Org. Coat. 2011, 71, 173-180. [CrossRef]

11. Hu, R.-G.; Zhang, S.; Bu, J.-F.; Lin, C.-J.; Song, G.-L. Recent progress in corrosion protection of magnesium alloys by organic coatings. Prog. Org. Coat. 2012, 73, 129-141. [CrossRef]

12. Bessières, J.; Maurin, V.; George, B.; Molina, S.; Masson, E.; Merlin, A. Wood-coating layer studies by X-ray imaging. Wood Sci. Technol. 2013, 47, 853-867. [CrossRef]

13. Wuzella, G.; Kandelbauer, A.; Mahendran, A.R.; Teischinger, A. Thermochemical and isoconversional kinetic analysis of a polyester-epoxy hybrid powder coating resin for wood based panel finishing. Prog. Org. Coat. 2011, 70, 186-191. [CrossRef]

14. Badila, M.; Jocham, C.; Zhang, W.; Schmidt, T.; Wuzella, G.; Müller, U.; Kandelbauer, A. Powder coating of veneered particle board surfaces by hot pressing. Prog. Org. Coat. 2014, 77, 1547-1553. [CrossRef]

15. TIGER Coatings $\mathrm{GmbH} \&$ Co. KG. Drylac®Produktdatenblatt: SERIE 530. Available online: http: / / www.tiger-coatings.com/fileadmin/user_upload/documentmanager_tiger-coatings_com/product-datasheets/tiger-drylac/wood/TIGER_PDS_series530_1183_dt.pdf (accessed on 24 July 2017).

16. Wallenhorst, L.M.; Loewenthal, L.; Avramidis, G.; Gerhard, C.; Militz, H.; Ohms, G.; Viöl, W. Topographic, optical and chemical properties of zinc particle coatings deposited by means of atmospheric pressure plasma. Appl. Surf. Sci. 2017, 410, 485-493. [CrossRef]

17. Gascón-Garrido, P.; Mainusch, N.; Militz, H.; Viöl, W.; Mai, C. Effects of copper-plasma deposition on weathering properties of wood surfaces. Appl. Surf. Sci. 2016, 366, 112-119. [CrossRef]

18. AkzoNobel Powder Coatings B.V. Product Data Sheet: Interpon 610. Available online: http://www.interpon. de/interpon_tds/interpon-610/ (accessed on 14 August 2017).

19. ASTM D4541-02 Standard Test Method for Pull-Off Strength of Coatings Using Portable Adhesion Testers; ASTM International: West Conshohocken, PA, USA, 2002. 
20. DIN EN ISO 4624:2016-08 Paints and Varnishes_Pull-off Test for Adhesion (ISO 4624:2016); European Committee for Standardization: Brussels, Belgium, 2016.

21. DIN EN ISO 2813:2015-02 Paints and Varnishes-Determination of Gloss Value at $20^{\circ}, 60^{\circ}$ and $85^{\circ}$ (ISO 2813:2014); European Committee for Standardization: Brussels, Belgium, 2015.

22. George, G.A. High resolution XPS of organic polymers-The scienta ESCA 300 data base. Polym. Int. 1994, 33, 439-440. [CrossRef]

23. Marschewski, M.; Otto, C.; Wegewitz, L.; Höfft, O.; Schmidt, A.; Maus-Friedrichs, W. Adsorption analysis of thin films of terephthalic acid on Au and Al studied by MIES, UPS and XPS. Appl. Surf. Sci. 2015, 339, 9-14. [CrossRef]

24. Franke, M.; Marchini, F.; Zhang, L.; Tariq, Q.; Tsud, N.; Vorokhta, M.; Vondráček, M.; Prince, K.; Röckert, M.; Williams, F.J.; et al. Temperature-dependent reactions of phthalic acid on Ag(100). J. Phys. Chem. C 2015, 119, 23580-23585. [CrossRef]

25. Stepanow, S.; Strunskus, T.; Lingenfelder, M.; Dmitriev, A.; Spillmann, H.; Lin, N.; Barth, J.V.; Wöll, C.; Kern, K. Deprotonation-driven phase transformations in terephthalic acid self-assembly on $\mathrm{Cu}(100)$. J. Phys. Chem. B 2004, 108, 19392-19397. [CrossRef]

26. Davies, M.C.; Khan, M.A.; Domb, A.; Langer, R.; Watts, J.F.; Paul, A.J. The analysis of the surface chemical structure of biomedical aliphatic polyanhydrides using XPS and ToF-SIMS. J. Appl. Polym. Sci. 1991, 42, 1597-1605. [CrossRef]

27. DIN EN 319:1993-08 Particleboards and Fibreboards; Determination of Tensile Strength Perpendicular to the Plane of the Board; European Committee for Standardization: Brussels, Belgium, 1993.

(C) 2017 by the authors. Licensee MDPI, Basel, Switzerland. This article is an open access article distributed under the terms and conditions of the Creative Commons Attribution (CC BY) license (http:// creativecommons.org/licenses/by/4.0/). 